\title{
Magnetic resonance imaging of hearts with atrioventricular valve atresia or double inlet ventricle
}

\author{
I C Huggon, E J Baker, M N Maisey, A P Kakadekar, P Graves, S A Qureshi, M Tynan
}

\begin{abstract}
Objective-To investigate the effectiveness and limitations of magnetic resonance imaging in defining cardiac anatomy in patients with double inlet ventricle or atrioventricular valve atresia.

Design-Magnetic resonance images were reviewed retrospectively without reference to other morphological data.

Setting-A tertiary referral centre for paediatric cardiology.

Patients-18 patients (aged 8 days to 27 years) with a suspected univentricular atrioventricular connection.

Methods-Imaging by a $1.5 \mathrm{~T}$ whole body magnetic resonance system with imaging planes adjusted to individual patient anatomy to best define the cardiac morphology. A complete sequential diagnosis obtained from an independent interpretation of the images was compared with the diagnosis obtained from cross sectional echocardiography and angiocardiography.
\end{abstract}

Results There was substantial accord between the diagnosis from magnetic resonance alone and that from other methods. In the six instances where there was not accord the magnetic resonance diagnosis was considered to be correct in two cases and incorrect in three cases. In the remaining case no consensus could be reached. In eight patients magnetic resonance imaging provided anatomical information additional to that from other methods. The strengths of magnetic resonance were in imaging the pulmonary arteries and their abnormalities and identifying juxtaposed atrial appendanges but there were some deficiencies in identifying Blalock-Taussig shunts.

Conclusion-Magnetic resonance imaging provided detailed information about all aspects of cardiac morphology in patients with a suspected diagnosis of univentricular atrioventricular connection. Often it provided additional information to echocardiography. Its use in selected patients should give valuable complementary information.

(Br Heart J 1992;68:313-9)

The optimum management of patients with congenital heart disease depends on obtaining a precise anatomical diagnosis. ${ }^{12}$ While cross sectional echocardiography remains an important technique for obtaining this anatomical information, magnetic resonance imaging has recently been shown to be an invaluable adjunct in the assessment of congenital malformations of the heart and great vessels. $^{3-5}$ In this study we review our experience with magnetic resonance imaging in the diagnosis of congenital cardiac malformations in which there was an abnormality of atrioventricular connection. In each patient a diagnosis of univentricular atrioventricular connection was considered in the initial differential diagnosis, though in some cases the final diagnosis was revised. The diagnoses made by magnetic resonance imaging were compared with those made by echocardiography, and where applicable, by angiocardiography.

\section{Patients and methods}

Eighteen patients (aged eight days to 27 years, median 2.5 years) underwent magnetic resonance imaging with a $1.5 \mathrm{~T}$ whole body imaging system (Gyroscan, Philips Medical Systems). We sedated the younger children with chloral hydrate $(100 \mathrm{mg} / \mathrm{kg})$ or chloral hydrate $(75 \mathrm{mg} / \mathrm{kg})$ combined with trimeprazine $(2 \mathrm{mg} / \mathrm{kg})$. The scans were gated from the electrocardiogram by means of electrodes placed close to the cardiac apex to reduce flow distortion of the signal. The trigger delay time was $15 \mathrm{~ms}$. All of the patients were in sinus rhythm except one who had complete heart block with a regular ventricular rate of 70/min. A T1 weighted spin-echo sequence was used in all of the patients. Echo times were 20 or $30 \mathrm{~ms}$ and the time to repeat was determined by the software based on the patients heart rate and varied between 312 and $500 \mathrm{~ms}$. Generally, four phase encoding steps were used, but where this would have entailed an acquisition time of more than about six minutes only two were used. The field of view ranged from 101 to $450 \mathrm{~mm}$ and the final matrix size was 256 by 256 . Infants were imaged inside a proton head coil, and a body coil was used for the larger children and young adults. Each patient was first scanned in a coronal plane in a non-gated mode and the resulting images were then used to plan the plane of subsequent scans. Magnetic resonance imaging allows scanning in any plane and the simultaneous acquisition of several 
parallel image slices within that plane. Angles and offsets of the individual imaging planes were selected for each patient by a cardiologist present at the investigation, in the light of previously acquired images and knowledge of the anatomy already established including the results of previous echocardiography. The planes were chosen first to image areas of the anatomy about which there was most uncertainty, other areas being imaged as time allowed. The slice thickness ranged from $5 \mathrm{~mm}$ to $10 \mathrm{~mm}$ and was chosen according to the size of the patient. Thinner slices can resolve smaller structural details than thicker slices but are associated with a higher signal to noise ratio and deterioration in image quality. The number of slices in a particular plane was chosen to include all areas of interest.

We studied patients with an abnormality of atrioventricular connection in whom a diagnosis of a univentricular atrioventricular connection was considered in the initial differential diagnosis. Limited access to $M R$ imaging sessions meant that only about half the patients eligible for inclusion in the series during the period of the study could be scanned. Patients in whom more complete definition of the complex cardiac anatomy was required were selected for magnetic resonance imaging. In several patients, determination of the anatomy of the pulmonary arteries was the main object of the scan and defining the intracardiac anatomy was a secondary consideration. No patient had had definitive surgery before scanning but 11 had previously had one systemic to pulmonary shunt and two patients had had two shunts. Two patients had had pulmonary artery banding, one an atrial septectomy, and one repair of coarctation. All patients had clinical evaluation and cross sectional and Doppler echocardiography. Angiocardiography was performed when clinically indicated.

Table 1 Sequential segmental diagnosis from magnetic resonance imaging

\begin{tabular}{|c|c|c|c|}
\hline $\begin{array}{l}\text { Patient } \\
\text { number }\end{array}$ & $\begin{array}{l}\text { Atrioventricular } \\
\text { connection }\end{array}$ & $\begin{array}{l}\text { Ventriculoarterial } \\
\text { connection }\end{array}$ & Comments \\
\hline 1 & DIRV & $\begin{array}{l}\text { Double outlet right } \\
\text { ventricle }\end{array}$ & Common atrioventricular valve \\
\hline 2 & Absent right & Discordant & $\begin{array}{l}\text { Double inlet left ventricle on } \\
\text { echocardiography }\end{array}$ \\
\hline 3 & Absent right & $\begin{array}{l}\text { Double outlet right } \\
\text { ventricle }\end{array}$ & $\begin{array}{l}\text { Hypoplastic right atrioventricular valve and } \\
\text { concordant atrioventricular connection }\end{array}$ \\
\hline 4 & DILV & Discordant & \\
\hline 5 & Absent right & Concordant & Pulmonary atresia \\
\hline $\begin{array}{l}6 \\
7\end{array}$ & $\begin{array}{l}\text { DILV } \\
\text { DILV }\end{array}$ & $\begin{array}{l}\text { Discordant } \\
\text { Discordant }\end{array}$ & Right ventricle to the left of left ventricle \\
\hline 8 & DILV & $\begin{array}{l}\text { Double outlet right } \\
\text { ventricle }\end{array}$ & Juxtaposed atrial appendages \\
\hline 9 & Absent right & Concordant & \\
\hline 10 & Concordant & Concordant & $\begin{array}{l}\text { Juxtaposed atrial appendages, imperforate } \\
\text { right atrioventricular valve }\end{array}$ \\
\hline $\begin{array}{l}11 \\
12\end{array}$ & $\begin{array}{l}\text { Absent right } \\
\text { Concordant }\end{array}$ & $\begin{array}{l}\text { Concordant } \\
\text { Double outlet right } \\
\text { ventricle }\end{array}$ & $\begin{array}{l}\text { Pulmonary atresia } \\
\text { Imperforate left atrioventricular valve }\end{array}$ \\
\hline $\begin{array}{l}13 \\
14\end{array}$ & DILV & Concordant & Common atrioventricular valve \\
\hline 15 & DILV & $\begin{array}{l}\text { Single outlet right } \\
\text { ventricle }\end{array}$ & Pulmonary atresia \\
\hline $\begin{array}{l}16 \\
17\end{array}$ & $\begin{array}{l}\text { Absent right } \\
\text { DIRV }\end{array}$ & Concordant & \\
\hline $\begin{array}{l}17 \\
18\end{array}$ & Concordant & $\begin{array}{l}\text { Concordant } \\
\text { Concordant }\end{array}$ & $\begin{array}{l}\text { Pulmonary atresia, imperforate right } \\
\text { atrioventricular valve }\end{array}$ \\
\hline
\end{tabular}

DIRV, double inlet left ventricle; DILV, double inlet left ventricle.
INTERPRETATION OF THE MAGNETIC RESONANCE SCANS

The images were acquired with the help of any available diagnostic information on the patient. For the purposes of this study, however, they were reviewed without reference to any previous information available on the patients. Each scan was reported according to the following protocol. First the technical details of the scan acquisition were noted. Then the cardiac morphology was analysed by the sequential approach and the associated anomalies were recorded as follows.

\section{Venous connections}

Systemic and pulmonary veins were identified on the images and each followed to its draining atrium, which was then identified as described below.

\section{Atrial anatomy}

The atrial arrangement was assessed according to the morphology of the atrial appendages, the right atrial appendage being identified by a wide base and triangular shape and the left by a narrow base and tubular shape. The relation of the great vessels at the level of the diaphragm and the anatomy of the bronchi were recorded where available. Defects within the atrial septum were noted.

\section{Atrioventricular connection}

The atrioventricular connection was determined by identifying the number of atrioventricular valves present and the morphology of the atria and the ventricles that they connected. Where a ventricular cavity was separated by tissue from an atrial cavity, the intervening tissue was identified either as an extension of bright fatty sulcal tissue, indicating an absent connection, or as an imperforate valve.

\section{Ventricular anatomy}

The ventricular morphology was identified primarily by the trabecular pattern. In cases of uncertainty the shape of the ventricles, their relative positions, and the number and the insertion of the papillary muscles were considered. The site and size of any ventricular septal defects were noted.

\section{Ventriculoarterial connection}

The pulmonary artery and aorta were identified by their location and branching patterns and traced back to the ventricle of origin by following their course through several image slices if necessary. The presence of a complete muscular infundibulum and of stenosis or atresia were documented.

\section{The great arteries}

The relation of the aorta and the pulmonary artery at the valve level were established. The course of the aortic arch was followed for any abnormality. The pulmonary artery and its main branches were identified in transverse and oblique sagittal or coronal images. The size of the arteries and any stenosis were recorded. Aorto-pulmonary shunts, when present, were identified on these images. 
Table 2 Additional information from magnetic resonance imaging

\begin{tabular}{cl}
\hline $\begin{array}{c}\text { Patient } \\
\text { number }\end{array}$ & Additional information obtained \\
\hline 4 & $\begin{array}{l}\text { Pulmonary artery anatomy shown more clearly than } \\
\text { on angiography }\end{array}$ \\
5 & $\begin{array}{l}\text { Left pulmonary artery stenosis associated with left } \\
\text { Blalock shunt }\end{array}$ \\
8 & $\begin{array}{l}\text { Juxtaposed atrial appendanges } \\
\text { Stenosis of the left pulmonary artery }\end{array}$ \\
10 & $\begin{array}{l}\text { Juxtaposed atrial appendanges } \\
\text { Absent left pulmonary artery }\end{array}$ \\
11 & $\begin{array}{l}\text { Pulmonary artery anatomy demonstrated (no } \\
\text { angiogram performed) }\end{array}$ \\
15 & $\begin{array}{c}\text { Absence of substantial central pulmonary arteries } \\
\text { (later confirmed by angiogram) }\end{array}$ \\
\hline
\end{tabular}

The images were reviewed by considering each set of slices together and following structures identified in one slice through the adjacent slices in order to appreciate fully the relation and connections.

Subsequently the results of this assessment of the magnetic resonance diagnosis were compared with the diagnoses made by echocardiography and angiocardiography. Where the diagnoses from magnetic resonance imaging and from other techniques did not accord the information from the magnetic resonance imaging, echocardiography, and angiocardiography was reviewed together by two of the authors to arrive at a consensus diagnosis. Necropsy results were reviewed where available.

\section{Results}

Scans of diagnostic quality were obtained in all the patients. Table 1 summarises the findings in individual patients. There was considerable motion artefact in four of the studies but this did not affect interpretation of the scans.

In 12 of 18 patients there was no substantial discord between the initial interpretation of the magnetic resonance scan and the information available from cross sectional echocardiography and angiocardiography. In six of 18 cases there was substantial discord. In eight of 18 patients the magnetic resonance scan provided additional anatomical information not available from the other techniques (table 2). In those patients in whom examinations did

Table 3 Lack of accord between magnetic resonance imaging and other techniques

\begin{tabular}{|c|c|c|c|}
\hline $\begin{array}{l}\text { Patient } \\
\text { number }\end{array}$ & $\begin{array}{l}\text { Diagnosis from } \\
\text { magnetic resonance }\end{array}$ & $\begin{array}{l}\text { Diagnosis from } \\
\text { other techniques }\end{array}$ & $\begin{array}{l}\text { Conclusion from } \\
\text { consensus diagnosis }\end{array}$ \\
\hline 2 & $\begin{array}{l}\text { Absent right } \mathrm{AV} \\
\text { connection }\end{array}$ & $\begin{array}{l}\text { Double inlet left } \\
\text { ventricle }\end{array}$ & $\begin{array}{l}\text { Magnetic } \\
\text { resonance } \\
\text { misinterpreted }\end{array}$ \\
\hline 3 & $\begin{array}{l}\text { Absent right } \mathrm{AV} \\
\text { connection }\end{array}$ & $\begin{array}{l}\text { Hypoplastic right } A V \\
\text { valve }\end{array}$ & $\begin{array}{l}\text { Magnetic } \\
\text { resonance } \\
\text { misinterpreted }\end{array}$ \\
\hline 3 & Right atrial isomerism & Usual atrial arrangement & $\begin{array}{l}\text { Magnetic } \\
\text { resonance } \\
\text { misinterpreted }\end{array}$ \\
\hline 8 & $\begin{array}{l}\text { Double outlet right } \\
\text { ventricle }\end{array}$ & $\begin{array}{l}\text { Double outlet left } \\
\text { ventricle }\end{array}$ & $\begin{array}{l}\text { Magnetic } \\
\text { resonance } \\
\text { correct }\end{array}$ \\
\hline 12 & $\begin{array}{l}\text { Imperforate left } A V \\
\text { valve }\end{array}$ & $\begin{array}{l}\text { Absent left AV } \\
\text { connection }\end{array}$ & $\begin{array}{l}\text { Magnetic } \\
\text { resonance } \\
\text { correct }\end{array}$ \\
\hline 17 & $\begin{array}{l}\text { Double inlet right } \\
\text { ventricle concordant } \\
\text { VA connection }\end{array}$ & $\begin{array}{l}\text { Double inlet left } \\
\text { ventricle discordant } \\
\text { VA connection }\end{array}$ & Undecided \\
\hline
\end{tabular}

AV connection, atrioventricular connection; VA connection, ventriculoarterial connection.

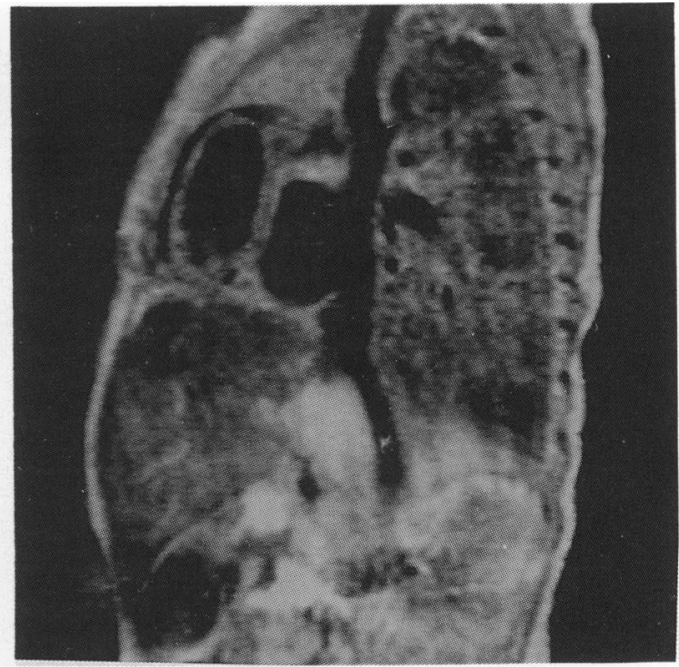

Figure $1 A$ sagittal slice from the scan of patient 13 showing the connection of inferior and superior caval veins to the right atrium.

not accord a consensus diagnosis reached after consideration of all the available information indicated that the magnetic resonance diagnosis was misleading in three patients but correct in two. In the remaining patient a consensus could not be reached because the angiographic and magnetic resonance findings were contradictory (table 3 ).

Postmortem pathology was available in only one of the patients (patient 13, table 1) and this confirmed correct interpretation of the magnetic resonance scan.

\section{VENOUS CONNECTIONS}

In 17 of the 18 patients the drainage of the superior and inferior caval veins into the right atrium (fig 1) and of the pulmonary veins into the left atrium (fig 2) was clearly shown. Scans of the remaining patient showed the inferior caval vein draining to the right atrium but the superior caval veins and pulmonary veins were not seen completely. A left-sided superior caval vein known to be present from echocardiography in one patient was not noted on the

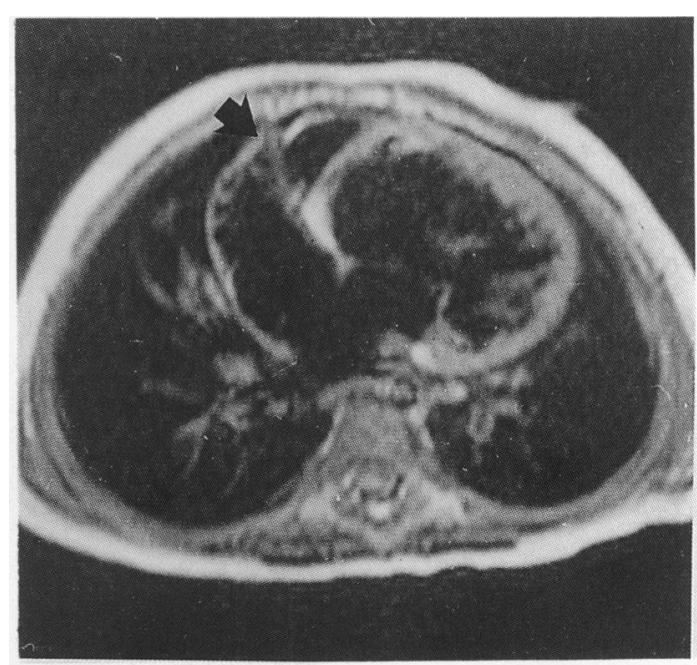

Figure 2 Drainage of pulmonary veins into the left atrium in patient 16. Right atrial appendage (indicated by the arrow), a large atrial septal defect, and dominant left ventricle are also shown. 
Figure 3

Morphologically left atrial appendage, indicated by

connecting to the dilated left atrium of patient 14. the arrow, shown

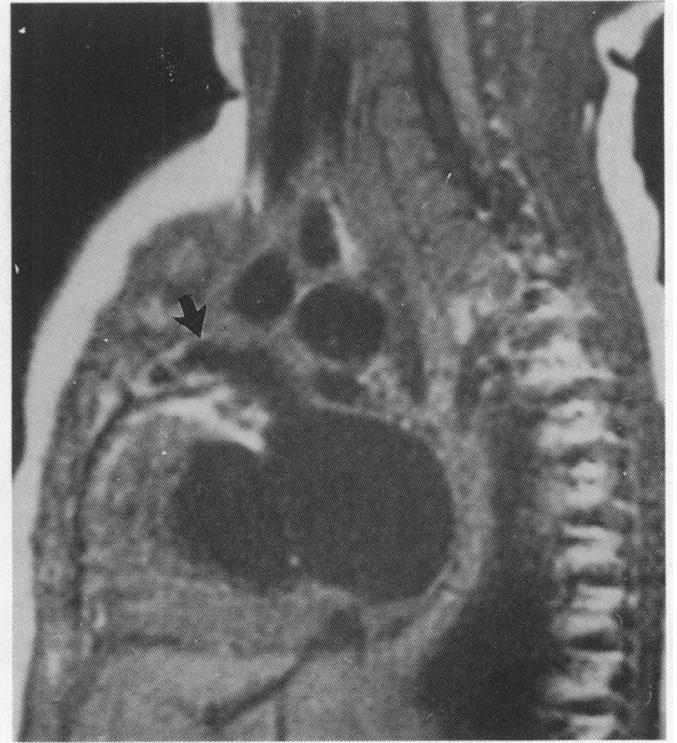

magnetic resonance images on the first interpretation but was identified on further review of the images.

\section{ATRIAL ANATOMY}

In all of the patients the relation of the aorta and the inferior caval vein at the diaphragm could be clearly demonstrated on transverse, coronal, or serial sagittal views.

In 11 of the 18 patients, both the atrial appendages could be identified as either morphologically right or left (figs 2 and 3). In a further six patients a morphologically right atrial appendage was shown on the right side but the left sided atrial appendage was not clearly shown. In one patient neither atrial appendage was adequately imaged. Of the 11 patients in whom both atrial appendages were identified one was initially considered to have right isomerism of the atrial appendages on the basis of the magnetic resonance scan alone but the diagnosis was revised to the usual arrangement when all the information was considered. The remaining 10 all had usual atrial arrangement. Two of the patients with the usual atrial arrangement had unsuspected juxtaposition of the atrial appendages. In one of these patients, surgical confirmation was avail-

Figure 4 Absent right connection. Sulcal fat can be seen as a bright line (arrow) separating the right atrium from the small right ventricle. Right atrial appendage is also shown and the morphological lef ventricle can be distinguished from the smaller morphological right ventricle (patient 14). able and in the second the magnetic resonance images provided the only evidence of juxtaposition.

The relative sizes of the atria were well seen in all of the patients. In seven a large atrial septal defect was shown but in the remainder it was not possible to confirm or exclude a defect. Because of its thinness relative to the thickness of the image slices, the atrial septum is subject to "dropout" on magnetic resonance images that is analogous to that seen with cross sectional echocardiography.

\section{ATRIOVENTRICULAR CONNECTION}

Magnetic resonance imaging showed the atrioventricular connection in all 18 patients. In 16 of these the initial interpretation of the images was correct whereas in two it was incorrect (one with a double inlet left ventricle and one with a hypoplastic right atrioventricular valve with concordant connection)

Of the 16 patients eight had double inlet ventricle, five had absent right-sided connection (fig 4), and three had concordant connection, but with an imperforate right-sided atrioventricular valve in two and an imperforate left sided atrioventricular valve in one (fig 5). The latter patient (patient 12, table 3) had been considered to have an absent left atrioventricular connection on echocardiography but was confirmed to have an imperforate valve after review of all the diagnostic information.

In six of the seven patients with double inlet left ventricles, the atrioventricular connections were correctly identified; the seventh was initially misinterpreted as an absent right connection on the magnetic resonance images (patient 2, table 3). Two patients had double inlet right ventricle diagnosed on magnetic resonance imaging. The diagnosis in one of these was confirmed by the other techniques but no consensus was reached about patient 17 because the angiograms seem to suggest a diagnosis of double inlet left ventricle.

In one patient the anatomy by magnetic resonance was thought to be that of absent right connection but on review the echocardiographic diagnosis of hypoplastic right atrioventricular valve was correct and the magnetic resonance images had been misinterpreted.

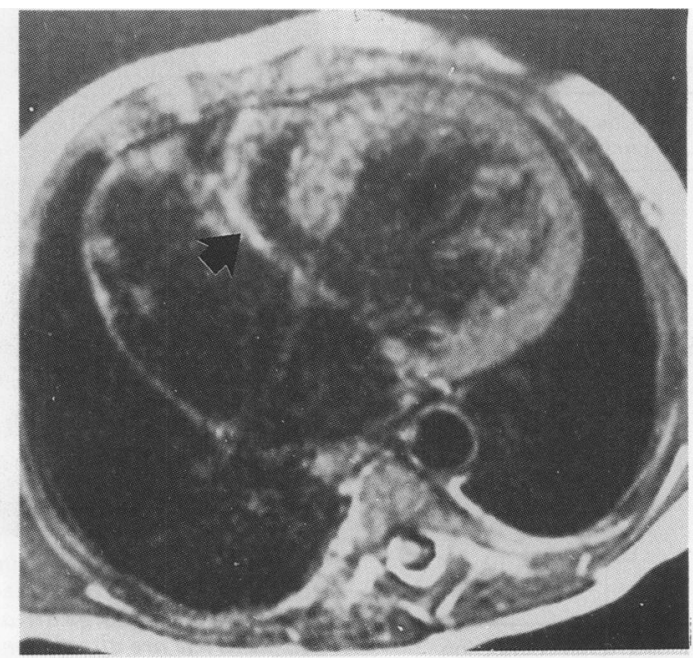

Figure 5 Imperforate left atrioventricular valve (patient 12). Note the absence of penetration of sulcal fat to the crux of the heart (arrow) in contrast to the absent right connection in fig 4. 
Figure 6 Oblique sagittal view of patient 17 showing a small smooth-walled left ventricle posteriorly and trabeculated right ventricle anteriorly. The angiogram was more suggestive of double inlet left ventricle than the double inlet right ventricle indicated by the magnetic resonance images. Right and left atrial appendages and a ventricular septal defect are also shown.

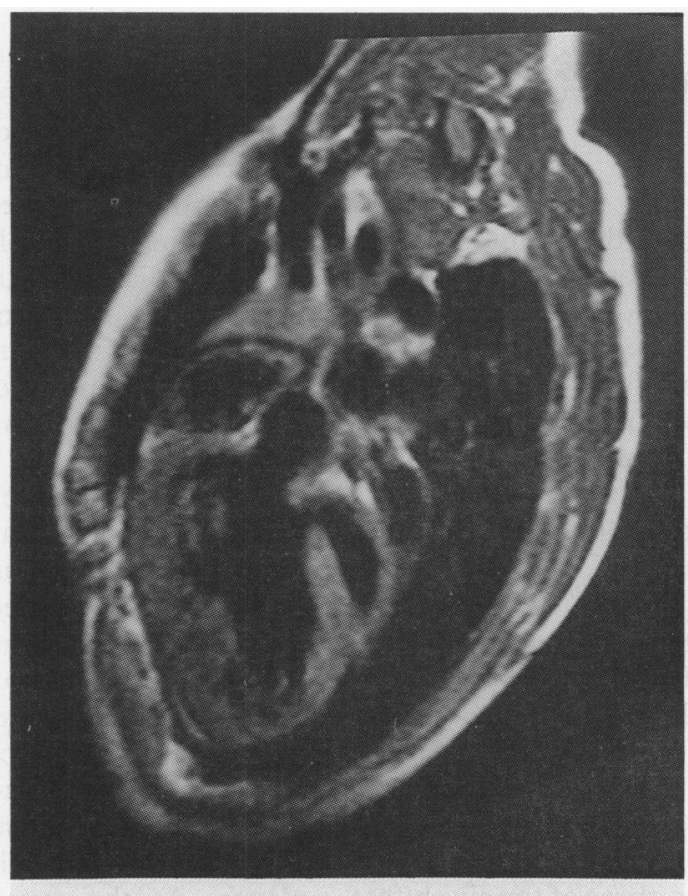

VENTRICULAR MORPHOLOGY

The ventricular morphology of one or both the ventricles could be determined by magnetic resonance in all patients. In 16 of the patients we determined the morphology by the trabecular pattern and in two by taking other features into account.

In eight patients the characteristic trabecular pattern could be identified in both the ventricles (figs 4 and 6), though in one of these patients (patient 17, table 3), with a double inlet connection, the angiographic and magnetic resonance findings were conflicting. In a further eight patients only the left ventricular trabeculations were identified, the right ventricle being very small. In the remaining two patients the trabecular pattern was not identified with certainty, but the ventricular morphology was inferred from the shape and the relative positions of the ventricles.

The predominance of patients with univentricular atrioventricular connection made the use of papillary muscle numbers and site of insertion as an indication of ventricular morphology inapplicable in most cases. In only five of the 18 patients were two distinct papillary muscles seen in the left ventricle and the septal attachments of the tricuspid valve tensor apparatus were seen in only three patients.

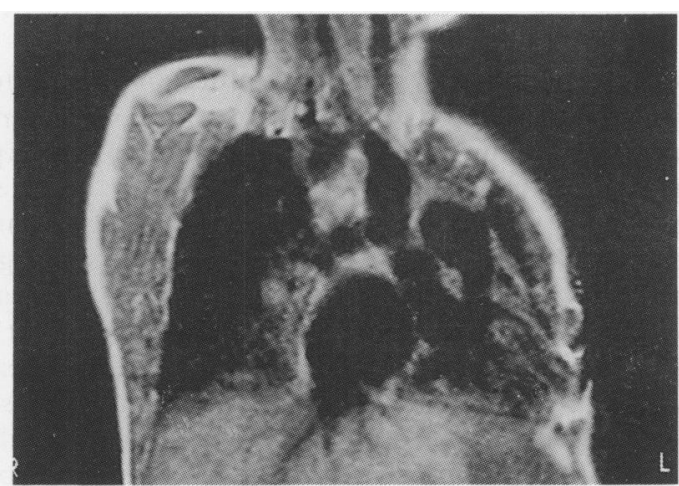

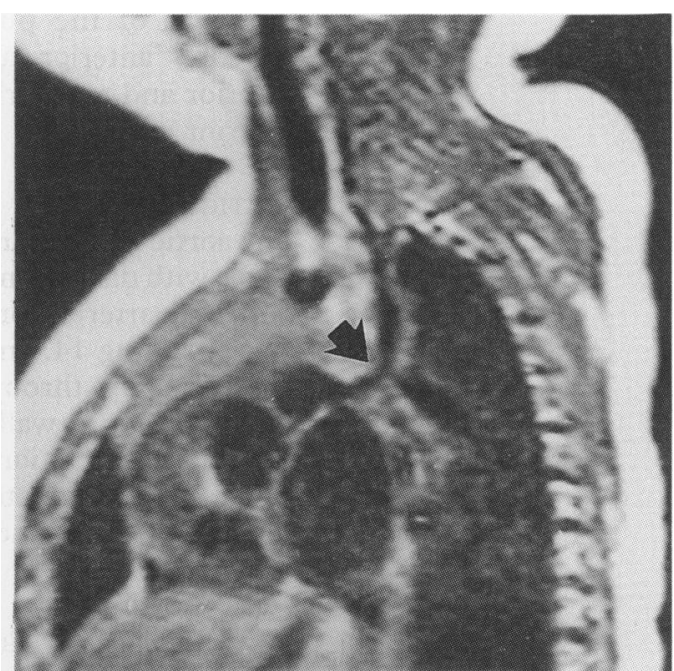

Figure 8 Left pulmonary artery in patient 3 can be seen to be distorted and stenosed at the site of a patent Blalock-Taussig shunt.

\section{RELATIVE POSITIONS OF THE VENTRICLES}

The right ventricle was anterior and/or superior to the left ventricle in 17 . In the remaining patient, with dextrocardia and double inlet left ventricle, the right ventricle was directly to the left of the morphologically left ventricle (patient 6).

\section{VENTRICULAR SEPTAL DEFECTS}

The site and size of a ventricular septal defect was determined in 14 patients but the rims of the defect were not sufficiently well defined to determine the size or position of a defect in the remaining three where a defect was known to be present.

\section{VENTRICULOARTERIAL CONNECTION}

In all of the patients the type of the ventriculoarterial connection was correctly determined (table 1). Nine patients had a concordant ventriculoarterial connection, four had a discordant connection, four had a double outlet right ventricle and one had a single outlet aorta arising from the right ventricle. Figure 7 shows the double outlet right ventricle in patient 1 . In one patient (patient 8) the echocardiogram suggested double outlet left ventricle, but the magnetic resonance imaging showed double outlet right ventricle, which was the correct diagnosis on review.

The infundibular morphology was well demonstrated in all the patients. Four patients had a bilateral complete muscular infundibulum, of whom two had a double outlet right ventricle and one had a concordant and one a discordant ventriculoarterial connection. All of the three patients with only a subaortic infundibulum had discordant ventriculoarterial connection. A complete subpulmonary infundibulum was identified in the remaining 11 patients.

\section{GREAT ARTERIES}

The relation of the great arteries at the level of their valves was defined in all patients except one, in whom the main pulmonary artery was entirely absent. The aorta was posterior and to 
the right of the pulmonary artery in seven patients, anterior and to the left in four, anterior and to the right in three, and directly anterior in three.

\section{AORTIC ARCH}

The aortic arch was right sided in four patients (three with discordant and one with concordant ventriculoarterial connection) and left sided in the remaining 14 . In 11 patients the arch was widely patent throughout its course. In one patient the aortic wall was irregular because of a previous coarctation repair but the aortic lumen was adequate. In the remaining six patients views of the complete arch were not obtained.

\section{AORTOPULMONARY SHUNTS}

Thirteen patients had shunts, in two cases bilaterally. A right Blalock-Taussig shunt was seen on the scans of three patients, a left Blalock-Taussig shunt in six, and none in nine (fig 8). On a further review of the scans when the information about the presence of shunts was available to the observer, three of the six shunts missed on the first review could be identified: the remaining three shunts had not been imaged.

\section{PULMONARY ARTERIES}

In 14 patients the pulmonary arteries were seen well enough to assess their size and in four patients one or both pulmonary arteries were not visualised. In two of these four patients, the pulmonary artery was absent on angiography. In the remaining two the failure to identify the pulmonary arteries was attributed to the optimum image planes not being selected.

Discrete stenosis was shown in the left pulmonary artery in four patients and in the right pulmonary artery in two (fig 8). In one patient the main pulmonary artery was absent and in two the site of a pulmonary artery band was seen. It was generally possible to image the right and left pulmonary arteries as far as the division of the major branches, the limiting factor being respiratory movement that blurred the image distally.

\section{Discussion}

Magnetic resonance imaging is a safe, noninvasive method of obtaining anatomical information in congenital heart disease and is applicable to all ages. It was shown to be of value initially in patients with coarctation of the aorta and ventricular septal defect ${ }^{356}$ and subsequently in patients with atrioventricular septal defect ${ }^{7}$ and patients with double outlet right ventricle. ${ }^{8}$ In this study we investigated the role of magnetic resonance imaging in patients with suspected univentricular atrioventricular connection. Our aim was not only to study the atrioventricular connection itself, but also to study the associated features that contribute to a full anatomical description and which may influence the subsequent clinical management.

We showed that high resolution images can be obtained in patients with a wide range of age and build and we successfully and satisfactorily demonstrated their complex anatomy. To achieve this we avoided restricting ourselves to the use of fixed orthogonal planes, with which others have reported limited success. ${ }^{45}$ The major advantages of magnetic resonance imaging over both cross sectional echocardiography and angiocardiography are that any plane or series of planes of the heart can be imaged, irrespective of the nature and depth of the interposed tissues such as fat and lung, thus providing an unlimited "window" of access.

We planned each set of imaging planes separately, bearing in mind the anatomy already established for the patient, the position of the recognised landmarks on the images already obtained, and the aspects of the anatomy that required clarification. Optimum imaging sometimes required scanning planes that were oblique or double oblique with respect to the orthogonal planes. Thus during the scanning, the presence of a paediatric cardiologist with a thorough knowledge of the three dimensional anatomy of the heart was essential to plan the subsequent imaging planes. At the outset, it was important to concentrate on obtaining the appropriate images to clarify the anatomical issues in question. For example, to obtain satisfactory views of both the pulmonary arteries, transverse images that included the pulmonary artery bifurcation were followed up by oblique sagittal or coronal scans planned parallel to the right and left pulmonary arteries based on the transverse images obtained. However, usually a review of the images after a scan had been completed showed considerable additional information on the anatomy that had not specifically been sought. Furthermore, in several instances the magnetic resonance images provided information additional to that available from angiocardiography and cross sectional echocardiography alone (table 2). For example, the atrial morphological arrangement could often be determined directly from the scans rather than from potentially unreliable inference from the visceral or bronchial arrangement. ${ }^{9}$ However, particular care was required in interpretation, because in one case a left atrial appendage was mistakenly identified as a right one because of its oblique plane of section in the image. Juxtaposition of the atrial appendages was shown in two patients in whom this anomaly had not previously been suspected by echocardiography or angiocardiography. Such information could have been obtained angiographically, but only by using extra contrast injections and increasing the fluoroscopy time.

Failure of magnetic resonance imaging to demonstrate the anatomy correctly was attributable to inadequate views and/or misinterpretation of the scans. For instance, Blalock-Taussig shunts present on the images were not always recognised on the first interpretation. In other cases in which an absent right atrioventricular connection was diagnosed in error instead of double inlet left ventricle and hypoplastic right atrioventricular valve respectively, the magnetic resonance images were misinterpreted. It is important to 
distinguish between an absent right atrioventricular connection, characterised by bright sulcal fat separating the right atrium from the ventricle and the normal connection in which the image slice may have cut across the atrial and ventricular walls tangentially. ${ }^{10} 11$ Only by careful examination of all the slices to confirm that the sulcal fat extends through to the crux of the heart can this potential misinterpretation be avoided. The other source of failure to demonstrate structures adequately is the failure to obtain the image planes appropriate for the anatomical feature at issue. With the possible exception of very thin structures, such as the atrial septum, almost any cardiac structure can be satisfactorily imaged by magnetic resonance but in some cases specific and carefully planned imaging planes will be required to achieve this. Therefore a priority of the structures to be imaged should be decided upon before the scan starts so that more important information can be acquired first and less important information later.

Unlike angiocardiography, magnetic resonance imaging is non-invasive and does not use ionising radiation or contrast media. Furthermore, imaging of some structures such as pulmonary arteries by magnetic resonance can be superior to angiography, especially when the optimum site for contrast injection is not accessible to catheterisation. In contrast to echocardiography, magnetic resonance imaging produces a series of related tomographic slice images that include structures such as the spine and trachea, which act as reference points. Therefore, it is easier to appreciate the spatial relation of the heart within the chest and of the chambers and vessels to each other than with cross sectional echocardiography. This is especially true when images acquired previously by a different operator are reviewed. Although currently most magnetic resonance imaging protocols provide only information on structure it is possible to obtain quantitative flow measurements and thus haemodynamic information. ${ }^{12-14}$

Magnetic resonance can produce images of such quality and clarity that it might rightfully be considered the definitive method of structural diagnosis in life. However, it does not replace cross sectional echocardiography: it complements it. The relative low cost, efficacy, and the ease of use of cross sectional echocardiography ensures that it will remain the dominant diagnostic technique in congenital heart disease. The fact that the particular strengths, weaknesses, and limitations of cross sectional echocardiography differ considerably from those of magnetic resonance imaging determines a role for both the techniques. Magnetic resonance imaging should be used in particular in those patients with conditions and aspects of anatomy that cross sectional echocardiography does not image optimally and in patients in whom it will avoid the necessity for invasive investigation.

This research was supported by the British Heart Foundation We acknowledge Sir Philip and Lady Harris, the Special Trustees of Guy's Hospital and Philips Medical Systems for their help in funding this project. Dr J M Parsons and Dr A M Hayes helped in the acquisition of some of the iamges.

1 Rigby ML, Carvalho JS, Anderson RH, Reddington A. The investigation and diagnosis of tricuspid atresia. Int Cardiol 1990;27:1-17.

2 Sade RM, Fyfe DA. Tricuspid atresia: Current concepts in diagnosis and treatment. Pediatr Clin North Am 1990 37:151-69.

3 Parsons JM, Baker EJ, Hayes A, et al. Magnetic resonance imaging of the great arteries in infants. Int $J$ Cardio 1990;28:73-85.

4 Didier D, Higgins CB, Fisher MR, Osaki L, Silverman NH, Cheitlin MD. Congenital heart disease: Gated MR imaging in 72 patients. Pediatr Radiol 1986;158:227-35.

5 Baker EJ, Ayton V, Smith MA, et al. Magnetic resonance imaging of coarctation of the aorta in infants: use of high field strength. Br Heart $J$ 1989;62:97-101.

6 Baker EJ, Ayton V, Smith MA, et al. Magnetic resonance imaging at a high field strength of ventricular septal defects imaging at a high field strength of ventricul
in infants. Br Heart $J$ 1989;62:305-10.

7 Parsons JM, Baker EJ, Anderson RH, et al. Morphological evaluation of atrioventricular septal defects by magnetic evaluation of atrioventricular septal defects by
resonance imaging. Br Heart $J 1990 ; 64: 138-45$.

8 Parsons JM, Baker EJ, Anderson RH, et al. Double outlet right ventricle: Morphologic demonstration using nuclear magnetic resonance imaging. J Am Col Cardiol 1990;18: 168-78.

9 Caruso G, Becker AE. How to determine atrial situs? Considerations initiated by 3 cases of absent spleen with discordant anatomy between bronchi and atria. Br Heart 1979;41:559-67.

10 Jacobstein MD, Fletcher BD, Goldstein S, Riemenschneider TA. Magnetic resonance imaging in patients with hypoplastic right heart syndrome. Am Heart $J 1985$ 110:154-8.

11 Fletcher BD, Jacobstein MD, Abramowsky CR, Anderson RH. Right atrioventricular valve atresia: Anatomic evaluation with MR imaging. Am J Roentgenol 1986;148: evaluation

12 Underwood SR, Firmin DN, Rees RS, Longmore DB. Magnetic resonance velocity mapping. Clin Phys Physiol Magnetic resonance velocity map $1990 ; 11$ (suppl A):37-43.

13 Rees S, Firmin D, Mohiaddin R, Underwood R, Longmore $D$. Application of flow measurements by magnetic resonance velocity mapping to congenital heart disease. $\mathrm{Am}$ Cardiol 1989;64:953-6.

14 Moonen CTW, Van Zijl PCM, Frank JA, Le Bihan D, Becker ED. Functional magnetic resonance imaging in medicine and physiology. Science 1990;250:53-61. 